Article

\title{
Experimental Study of a New Precast Prestressed Concrete Joint
}

\author{
Xueyuan Yan ${ }^{\oplus}$, Suguo Wang * ${ }^{\mathbb{C}}$, Canling Huang, Ai Qi and Chao Hong \\ College of Civil Engineering, Fuzhou University, Fuzhou 350116, Fujian, China; yxy910@163.com (X.Y.); \\ huangcanling11@163.com (C.H.); qikai@fzu.edu.cn (A.Q.); hongchao94@163.com (C.H.) \\ * Correspondence: wangsuguo@foxmail.com; Tel.: +86-189-0690-7607
}

Received: 21 September 2018; Accepted: 3 October 2018; Published: 10 October 2018

Featured Application: Our research results can be applied in concrete structures, especially precast concrete structures.

\begin{abstract}
Precast monolithic structures are increasingly applied in construction. Such a structure has a performance somewhere between that of a pure precast structure and that of a cast-in-place structure. A precast concrete frame structure is one of the most common prefabricated structural systems. The post-pouring joint is important for controlling the seismic performance of the entire precast monolithic frame structure. This paper investigated the joints of a precast prestressed concrete frame structure. A reversed cyclic loading test was carried out on two precast prestressed concrete beam-column joints that were fabricated with two different concrete strengths in the keyway area. This testing was also performed on a cast-in-place reinforced concrete joint for comparison. The phenomena such as joint crack development, yielding, and ultimate damage were observed, and the seismic performance of the proposed precast prestressed concrete joint was determined. The results showed that the precast prestressed concrete joint and the cast-in-place joint had a similar failure mode. The stiffness, bearing capacity, ductility, and energy dissipation were comparable. The hysteresis curves were full and showed that the joints had good energy dissipation. The presence of prestressing tendons limited the development of cracks in the precast beams. The concrete strength of the keyway area had little effect on the seismic performance of the precast prestressed concrete joints. The precast prestressed concrete joints had a seismic performance that was comparable to the equivalent monolithic system.
\end{abstract}

Keywords: precast prestressed concrete joint; keyway area; reversed cyclic loading test; seismic performance; equivalent monolithic

\section{Introduction}

The precast concrete structure is one of the most important structural forms of modern architecture. A precast concrete structure has advantages over a cast-in-place concrete structure that include less wet work on site, better control of component quality, rapid construction, and good economic and environmental benefits. However, there are challenges posed to the application of precast concrete structures, such as poor connection reliability and structural integrity, that limit its use in seismic zones.

A precast concrete frame structure is distinguished from a cast-in-place structure by the connection method of columns, beams, and floors, and especially by the connection method of the beam-column joints. These joints significantly affect the seismic performance of the whole structure. The design principle of "strong joint weak component" is realized by ensuring that the assembled part of the beam-column joint region has sufficient strength, rigidity, and ductility to meet the requirements of bearing capacity and deformation capacity under the conditions of normal use and during earthquakes. 
The precast concrete frame joints must effectively transmit the bending moment and shear force between the precast components, and they also should have good ductility and energy dissipation capacity. Research on precast concrete structures mainly focused on the connection mode of joints, the mechanical properties of joints, and the seismic performance of prefabricated structures for different connection modes [1-17].

Maya et al. [1] studied precast elements that were joined by high-performance fiber reinforced concrete and short steel bars. The studies by Liu et al. [2] and Lee et al. [3] investigated precast concrete beam-column joints connected by sleeves and with anchor plates. Choi et al. [4] and Lu et al. [5] both proposed beam-column joints in which steel plates or U-shaped steel bars were placed in the joint zone and engineered cementitious composite (ECC) materials were poured. An improved hybrid $\mathrm{H}$-steel-precast concrete beam system was proposed by Yang et al. [6], and tests of five fixed-end beam specimens under reversed cyclic one-point concentrated top loads at the mid-span were performed to determine their bending capacity and ductility. Ersoy et al. [7] studied the seismic behavior of welded joints in a frame beam. Five specimens with welded joints and two monolithic reference specimens were tested to study their behavior under seismic action. Aninthaneni et al. [8] and Li et al. [9] developed joints with steel plates embedded at the precast beam ends and bolted to the precast columns. The precast joints with T-section steel plates that were pre-buried in the beam ends and connected by welded steel plates with post-pouring concrete at the joints were studied by Ketiyot et al. [10]. The works by Kim et al. [11] and $\mathrm{Wu}$ et al. [12] determined the performance of the joints with precast columns and steel beams. Yekrangnia et al. [13] evaluated the performance of a proposed steel connected precast concrete joint by experimental and numerical analysis. A precast concrete beam-column joint with energy-absorbing ductile connectors was developed by Englekirk et al. [14]. Ozturan et al. [15] performed a comparative test for four ductile, moment-resisting precast concrete frame connections and one monolithic concrete connection for high seismic zones. The studies of Vidjeapriya et al. [16] and Naik et al. [17] proposed a precast concrete beam-column joint with corbel and cleat angle, and a reversed cyclic loading test of the scaled model was performed.

In the above researches, the precast members were connected by steel bars or steel plates through overlapping, welding, or bolting. The seismic performance of most of these joints is comparable to the conventional cast-in-place joints. However, the introduction of prestressing on the precast concrete structure allows for the full use of the tensile and compressive strength of the member, improves the shear capacity of the structure, reduces the section height of the member, reduces the deformation, and ensures good crack closure and deformation recovery performance of the structure. Priestley et al. [18] studied the precast beam-column joints of partially unbonded prestressing tendons where the prestressing tendons were non-bonded within a certain range of the joint zone and the beam end. The results showed that the self-recovery ability of the joints was strong and the shear capacity was improved. The seismic behavior of prestressed prefabricated beam-column joints with energy-dissipation steel bars was investigated by Cheok et al. [19] and Wang et al. [20]. The self-recovering force was shown to be provided by the prestressing tendons and the energy consumed by the ordinary steel bars. Morgen et al. [21], Song et al. [22], and Rodgers et al. [23] proposed an unbonded post-tensioned precast concrete structure using dampers to supplement energy dissipation. The research of post-tensioned precast beam-to-column connections was conducted by Kaya et al. [24], and the performance of the joints at different stress levels through experiments were analyzed. Liu et al. [25] conducted pseudo-dynamic and quasi-static tests on a two-story precast prestressed concrete frame. The seismic performance of the post-tensioned prestressed joints was determined by performing reversed cyclic loading tests on two specimens with bonded tendons and two specimens with unbonded tendons by Xun et al. [26]. The test results showed that the test piece consumed less energy, but the residual deformation was smaller, and it had better recovery performance. Ha et al. [27] studied the performance of structures with U-shaped prestressed steel strands, precast columns, precast slabs, and topping concrete by testing three interior and three exterior joint specimens. Cai et al. [28,29] conducted reversed cyclic loading tests on precast prestressed concrete 
frame beam-column joints with different lengths of service hole. A steel-strand-anchored precast frame joint with embossed anchors was proposed by Guan et al. [30]. Parastesh et al. [31] introduced a ductile moment-resisting connection intended for high-intensity seismic zones. Im et al. [32] studied the parameters of a reinforced-concrete-emulated beam-column connection of a precast concrete moment frame with a U-shaped beam shell at the end of the beam. Eom et al. [33] proposed three plastic hinge relocation methods to improve the earthquake resistance of emulative precast concrete beam-column connections using PC (precast concrete) U-shell beams.

These studies show that the prestressing enhances the self-recovery ability of the joints, but some post-tensioned prestressed joints have poor energy dissipation capacity. Moreover, the connection of precast prestressed members, the interface treatment of the new-old concrete interfaces, the concrete strength, and their influences on the seismic performance of joints were not discussed comprehensively. Therefore, a precast prestressed concrete frame structure was studied in this paper. The reversed cyclic loading testing of three joints with different parameters was performed to observe the behavior and to obtain the hysteresis curve and skeleton curve of the joints. The stiffness, bearing capacity, ductility, and energy dissipation capacity of the joints were analyzed to investigate whether the seismic performance of the precast prestressed concrete frame joints met the requirements of the equivalent monolithic system. The influence of concrete strength in the keyway area on the performance of precast prestressed concrete joints was investigated. The reliability of the interface treatment method of the new-old concrete interface was studied. The force mechanism of precast prestressed concrete joints was analyzed. The reliability of transmitting force through the steel bar in the plastic hinge area was determined.

\section{Model Structure}

\subsection{Test Specimens}

The precast components of the precast prestressed concrete frame structure studied in this paper include the precast prestressed concrete laminated beams, precast concrete laminated slabs, and precast concrete columns. The precast columns can also be changed to cast-in-place concrete columns. The specialty of the precast prestressed concrete structure lies in its joint construction. The joints are composed of keyways, U-shaped steel bars, and cast-in-place concrete. When the beam-column joints are connected, the U-shaped steel bars passing through the core area overlap with the prestressing tendons in the keyway area at the end of the beam, and the precast beam and column are connected by post-pouring concrete. This design is conducive to joint construction, but the bar lap connection of the beam end is not ideal for the seismic resistance of the joint. Thus, the frame joint is a primary focus of seismic research on precast prestressed concrete structures. The structural form of the precast prestressed concrete joint is shown in Figure 1. This post-pouring integrated connection forms a new-old concrete interface between the precast beam and the post-pouring concrete. The integrity of the prefabricated structure was ensured by applying "manual chiseling" to the horizontal new-old concrete interface. The "shearing key" was applied to the vertical new-old concrete interface of the keyway area to enhance the adhesion of the precast member surface and the post-pouring concrete.

The presence of the keyway wall increases the difficulty of setting the concrete cover. The lap bars are not sufficiently in contact with the post-pouring concrete which results in a reduced bonding effect. In this paper, three joints were designed and tested; two were precast prestressed concrete joints, labeled PPCJ1 and PPCJ2, the third was a cast-in-place joint, labeled CIPJ. The joints PPCJ1 and PPCJ2 were placed in the keyway area with C40 and C50 concrete, respectively.

The precast prestressed concrete joints had the same reinforcement and section dimensions as the cast-in-place joint. The cross-section dimensions and reinforcement of the cast-in-place joint and precast prestressed concrete joints are shown in Figures 2 and 3. The thickness of the concrete-laminated layer for the precast prestressed concrete joints was $100 \mathrm{~mm}$, and this was the same as the thickness of the floor. The keyway area of the precast prestressed concrete joints was the area from the end of 
the precast beam to the edge of the column, and it had a length of $450 \mathrm{~mm}$ in this design to meet the requirements of steel anchoring. The keyway area did not reserve the keyway wall, and the U-shaped groove was formed by the formwork during construction with the beam end reinforcement being overlapped here. The prestressing tendon of the precast beam extended from the beam body to the edge of the column and had a hook that overlapped the U-shaped bar crossing the core area of the joint to transfer stress.

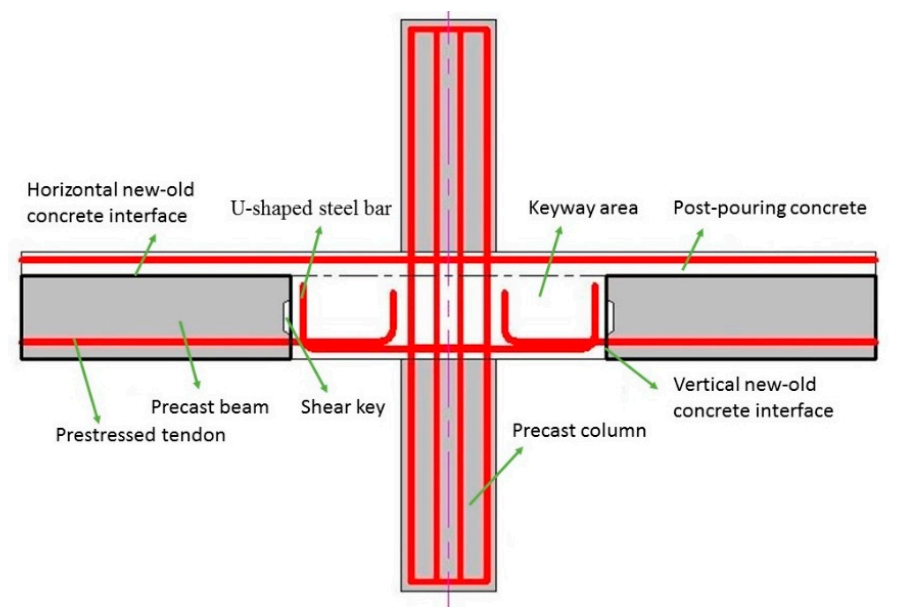

Figure 1. Precast prestressed concrete joint.
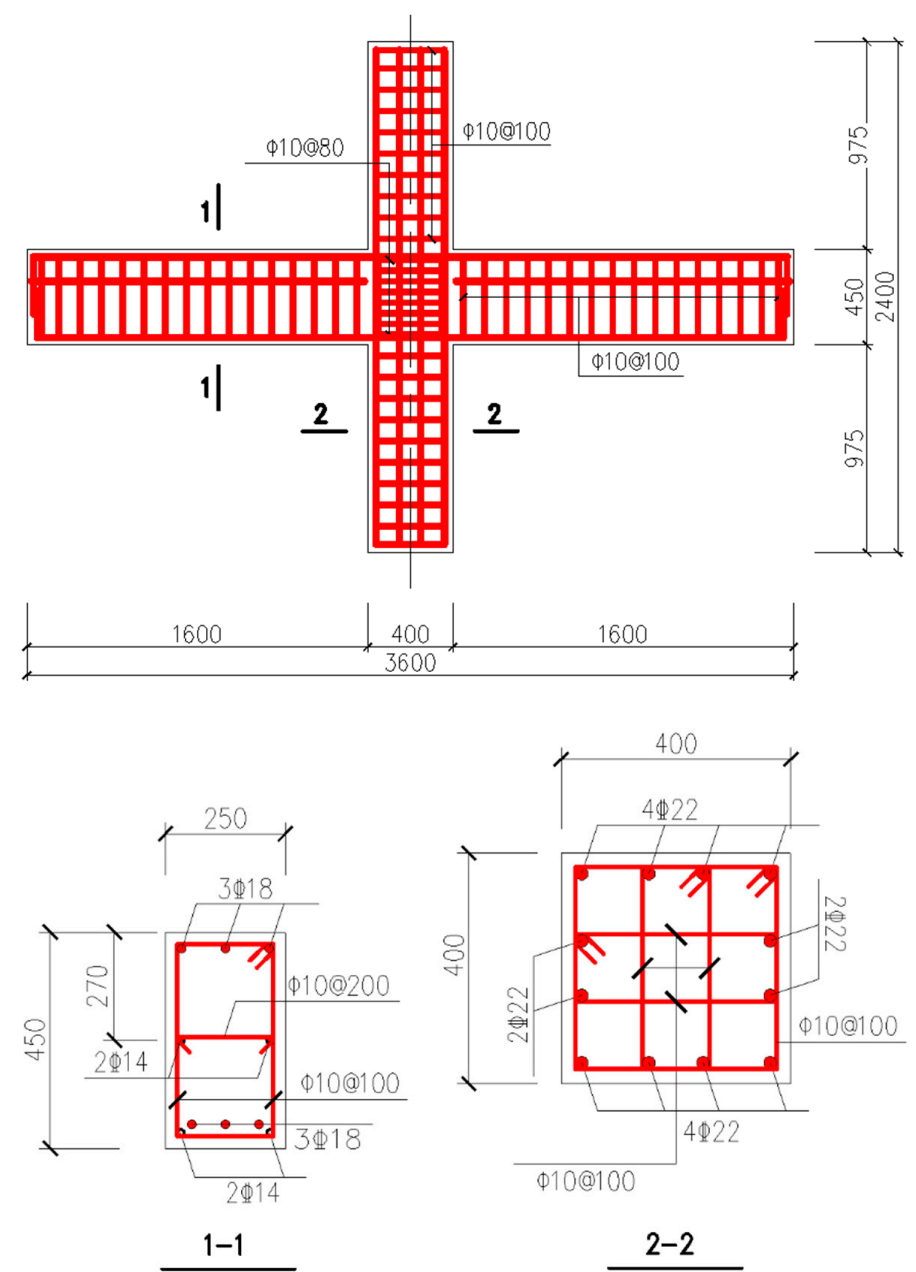

Figure 2. Reinforcement diagrams of the cast-in-place joint (unit: mm). 

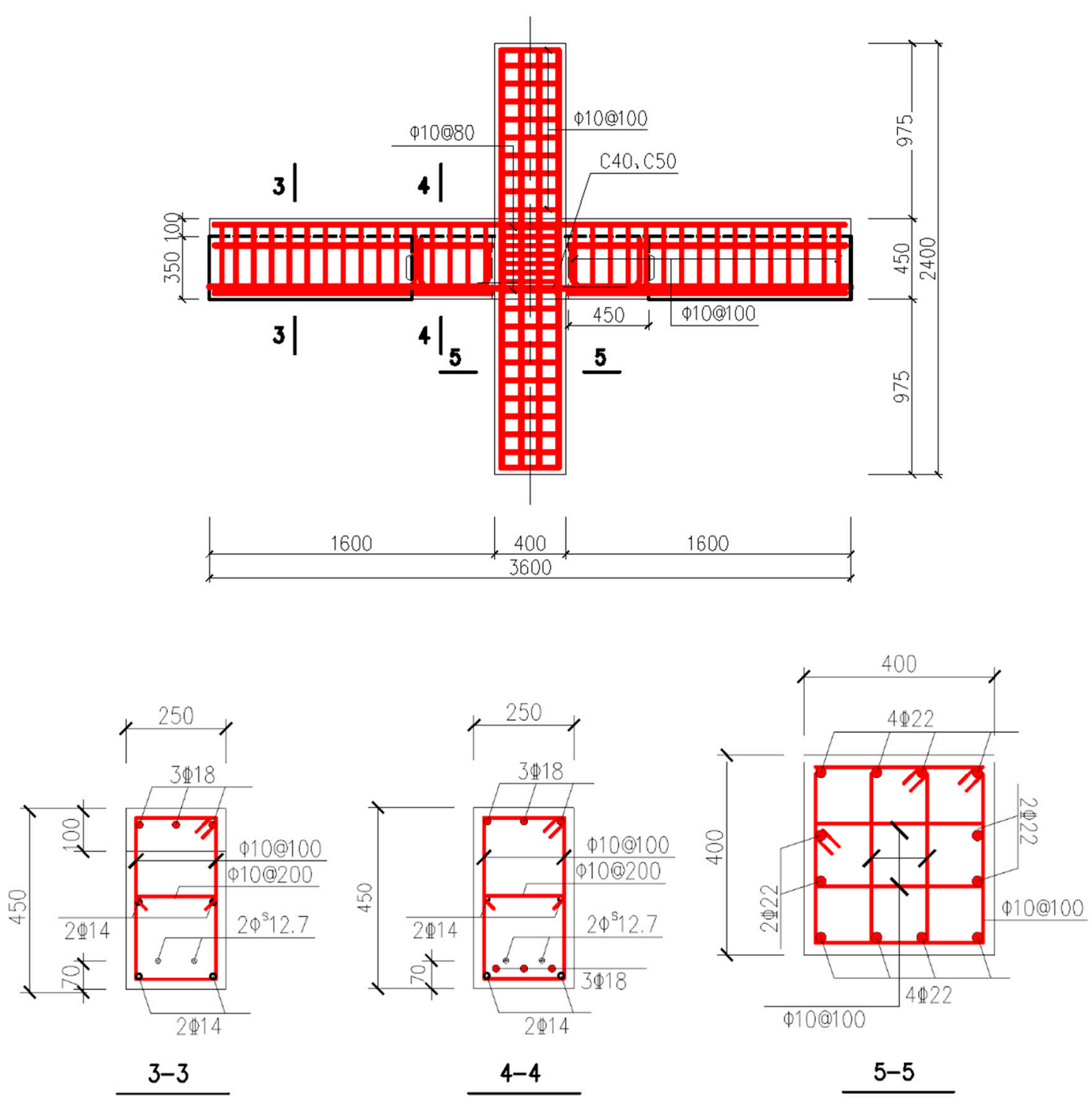

Figure 3. Reinforcement diagrams of precast prestressed concrete joints (unit: mm).

\subsection{Force Transmission Mode}

The difference between a precast prestressed concrete joint and a cast-in-place joint is mainly reflected in the new-old concrete interface and the connection force transmission mode of the steel bar. The precast prestressed concrete joint had a laminated beam that had a horizontally joined surface that engaged the cast-in-place concrete, and a vertical interface with the concrete of the keyway area. The performance of the new-old concrete interface affects the overall force of the laminated beam. A poor bonding capacity of the new-old concrete interface and the lack of a reliable force transmission mechanism result in cracking or damage of the new-old concrete interface earlier than in the cast concrete, thereby reducing the bearing capacity of the laminated beam. The shear transmission mechanisms for new-old concrete interfaces are the friction force, pinning shear, and shear resistance of shear key.

The friction force at the new-old concrete interface was generated when the concrete here was sheared causing a relative movement at the interface. When the shear force is less than the maximum friction of the new-old concrete interface, the concrete at both ends of the interface will not move, and the internal force of the laminated beam is transmitted normally at the section including the interface. In this case, a laminated beam has the same performance as a cast-in-place concrete beam. 
Shear resistance of the pinning bar occurs when the orthogonal reinforcements that traverse the interfaces do not have sufficient cohesive force, and the concrete surfaces at both ends of the interface cannot transfer the shear. Consequently, the steel bar which traverses the new-old concrete interface transmits the shear force by bending due to its dislocation deformation. The steel bar that produces this effect is called the pinning bar.

Shear resistance of the shear key develops from the concave and convex structure that is artificially placed at the boundary of the concrete. The shear is transmitted by the connection of the concave and convex concrete, and that limits the dislocation deformation of the boundary. The shear strength of the shear key is the smaller value between the shear force that causes the shear destruction of the keyway and the shear force that causes the compressive failure of the surface concrete for the shear key. The inclination angle of the boundary surface of the shear key has a large influence on the strength of the interface. When the inclination angle of the boundary surface is too large, the inclination surface is prone to slip failure, while, if it is too small, the convex part is prone to punching failure.

The horizontal new-old concrete interface is subjected to less shearing force and has a larger interface area. Therefore, "manual chiseling" was performed on the top of the precast beam to enhance the friction effect between the precast beam and the post-pouring concrete. The stirrup was used as an orthogonal steel bar that can act as a pinning bar when the interface has some slippage and serves as a second line of defense against shearing. The vertical new-old concrete interface of the keyway area mainly bears the vertical shearing force and bending moment of the interface. The bonding between the new and old concrete at the interface is weak, which causes the weakening of the tensile bearing capacity and shear bearing capacity of the interface. However, the compressive bearing capacity is not significantly affected. The shear key was set at the interface to bear most of the shearing force to ensure that shear bearing capacity is maintained. The structure of the keyway area is shown in Figure 4 .

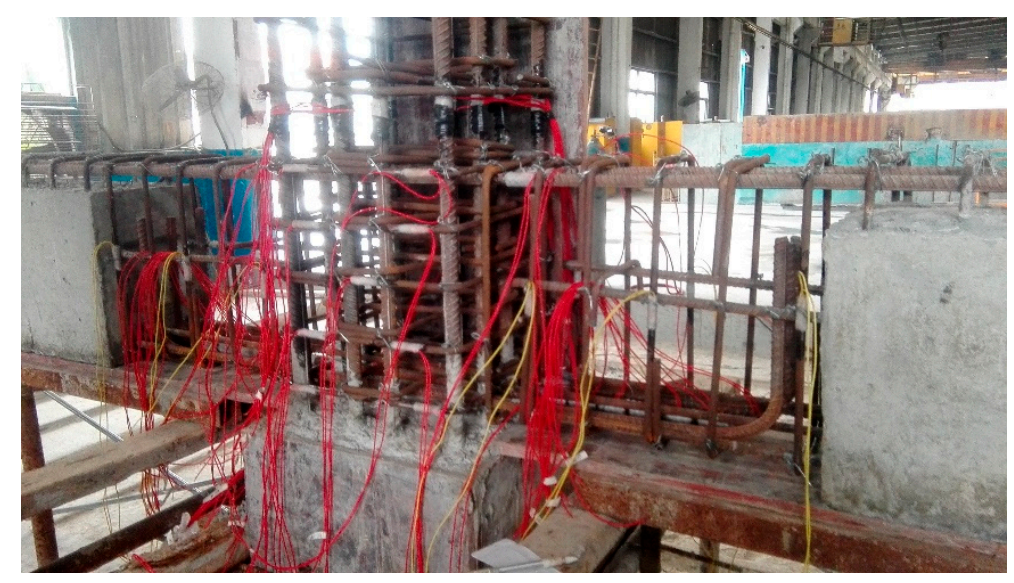

Figure 4. Construction of the keyway area of precast prestressed concrete joints.

\subsection{Concrete and Steel Properties}

The compressive strength and elastic modulus of the concrete were measured by the strength testing of standard prismatic $150 \mathrm{~mm} \times 150 \mathrm{~mm} \times 300 \mathrm{~mm}$ specimens for the same 28-day curing conditions. The results of concrete strength testing are listed in Table 1. The properties of the steel bars were tested, and the properties are given in Table 2.

Table 1. Material properties of concrete. PPCJ—precast prestressed concrete joint.

\begin{tabular}{cccc}
\hline Component & Strength Grade & Compressive Strength $f_{\mathrm{c}}(\mathbf{M P a})$ & Elastic Modulus $E_{\mathrm{c}}(\mathrm{GPa})$ \\
\hline Precast beam & C40 & 29.2 & 33.0 \\
Cast-in-place joint & C40 & 30.5 & 32.8 \\
PPCJ1 keyway & C40 & 30.5 & 32.8 \\
PPCJ2 keyway & C50 & 36.2 & 35.2 \\
\hline
\end{tabular}


Table 2. Reinforcement material properties.

\begin{tabular}{ccccc}
\hline Type of Reinforcement & $\begin{array}{c}\text { Yield Strength } f_{\mathbf{v}} \\
(\mathbf{M P a})\end{array}$ & $\begin{array}{c}\text { Ultimate Strength } \\
f_{\mathbf{u}}(\mathbf{M P a})\end{array}$ & $\begin{array}{c}\text { Elastic Modulus } \\
\boldsymbol{E}_{\mathbf{s}} \mathbf{( G P a )}\end{array}$ & $\begin{array}{c}\text { Elongation } \delta \\
\mathbf{( \% )}\end{array}$ \\
\hline $\begin{array}{c}\text { Stirrup }(\phi 10) \\
\text { Beam auxiliary steel bar }(14)\end{array}$ & 376 & 650 & 221.5 & 20.2 \\
$\quad \begin{array}{c}\text { Beam longitudinal } \\
\text { reinforcement }(18)\end{array}$ & 421 & 637 & 211.5 & 24.8 \\
$\quad \begin{array}{c}\text { Column longitudinal } \\
\text { reinforcement }(22)\end{array}$ & 462 & 644 & 209.7 & 23.7 \\
Prestressing tendon $\left(\phi^{\mathrm{s}}\right.$ 12.7) & 1842 & 621 & 206.2 & 22.6 \\
\hline
\end{tabular}

\subsection{Test Method}

The test was performed at the Fujian Institute of Engineering on an MTS loading system using two 500-kN electro-hydraulic servo actuators with a stroke of $\pm 20 \mathrm{~mm}$ for the reversed cyclic loading. The load was applied at the beam ends. A one-way rotating fixed hinge bearing was installed at the upper and lower column ends of the joint to simulate the effect of hinge restraints on the joint. The actuators were applied to two sides of the beam that caused the joint to bend under loading. The test set-up is shown in Figure 5.

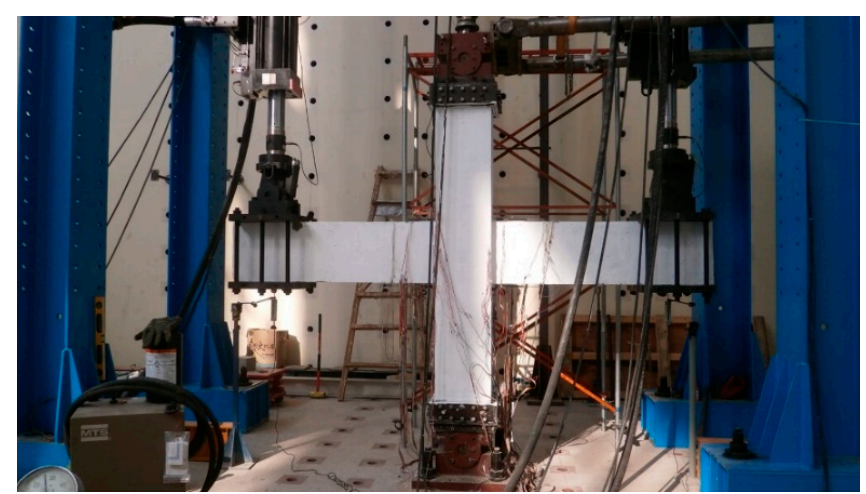

Figure 5. Test set-up of the joints.

The reversed cyclic loading test of the plane frame joints also allows for investigation of the beam end and the joint core area. The difficulty in calculating the bearing capacity of the precast joints limits the accuracy of determining the yield point during the test. Thus, a situation with the loading force being greater than the yield force may occur and cause the specimen to be damaged earlier than expected. Displacement control was used for the elastic loading phase and the plastic loading phase in this test, and the loading schemes for these phases are shown in Figure 6.

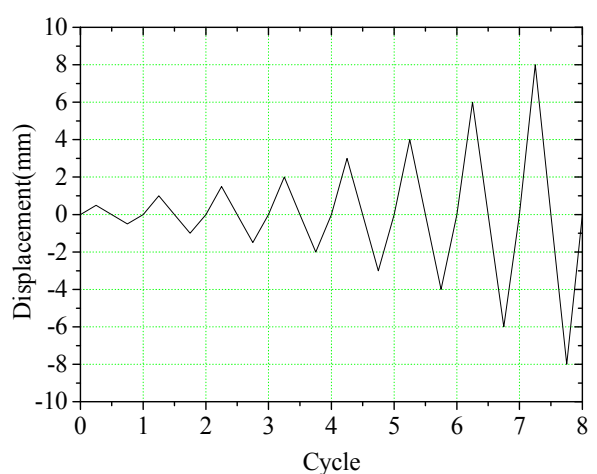

(a)

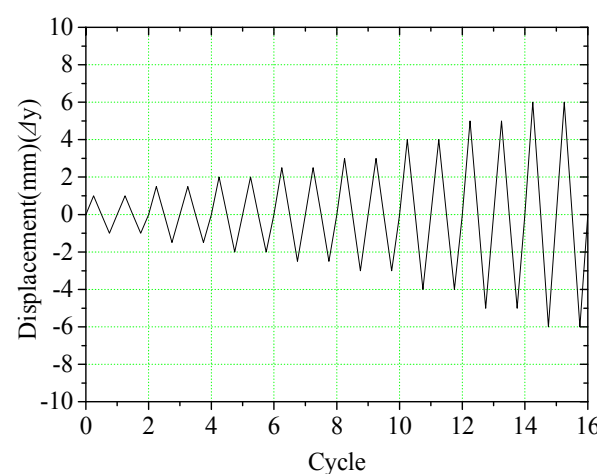

(b)

Figure 6. Loading scheme: (a) before yielding; (b) after yielding. 


\section{Test Results}

For convenience, the beams on either side of the joints are called the "left beam" and "right beam" with the displacement of the right beam representing the loading of the joint displacement. An upward displacement is considered to be positive. Before the formal loading, an axial pressure of $916 \mathrm{kN}$ was applied to the upper column end, and the axial compression ratio was 0.3 . The three joints were tested according to the loading scheme described in Section 2.3, and crack development was observed.

\subsection{Cast-In-Place Joint}

The force-displacement curve of the cast-in-place joint was linear prior to cracking of the specimen; the reciprocating curves almost coincide with each other, and the elastic behavior is obvious. The first vertical crack appeared at the edge of the top of the left beam when the displacement reached $2 \mathrm{~mm}$, and the crack width was $0.04 \mathrm{~mm}$. When the loading was reversed, a vertical crack also appeared at the edge of the bottom of the right beam, and the crack width was $0.06 \mathrm{~mm}$. At this time, the slope of the force-displacement curve began decreasing, and the positive and negative curves no longer coincided. These observations indicate that the cracking decreased the concrete's tensile strength. Thus, the load was transferred from the concrete to the steel bar and increased the strain in the steel bar. At a displacement of $4 \mathrm{~mm}$, the left and right beams of the joint were observed to have a second vertical crack that was approximately $100 \mathrm{~mm}$ long and was about $100 \mathrm{~mm}$ from the edge of the column. The distribution of the initial cracks for the cast-in-place beam is shown in Figure 7.

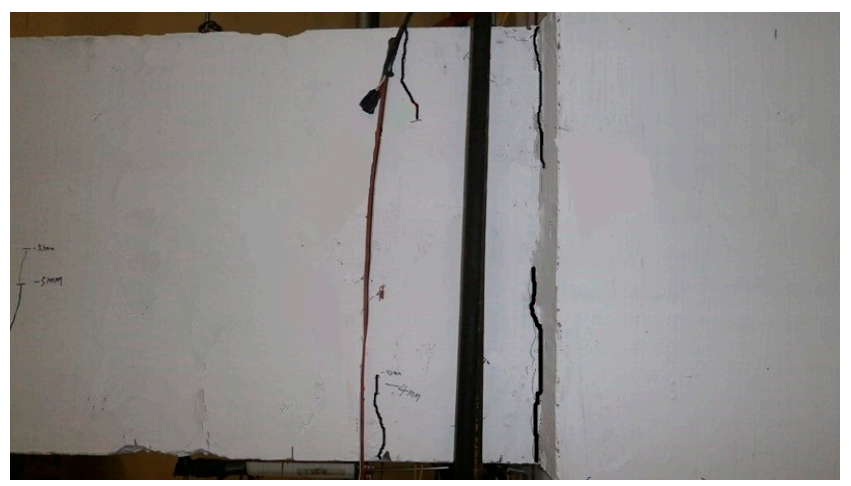

Figure 7. The initial cracking of the cast-in-place beam.

When the displacement was $6 \mathrm{~mm}$, cracks at the bottom of the beam began developing obliquely. These cracks were typical bending shear cracks. Increasing the displacement to $8 \mathrm{~mm}$ resulted in the longitudinal steel bar strain near the edge of the right beam of the joint to be greater than the yield strain of 0.0022 . Thus, the steel yielded during this displacement cycle. When the loading was reversed, the longitudinal reinforcements of the upper portion of the left beam near the edge of the column also began yielding. Thus, $\Delta=8 \mathrm{~mm}$ is taken as the yield displacement $\Delta y$. At this time, the number of yielded steel bars was small, and the plasticity had not fully developed. Therefore, the force-displacement curve of the joint did not yet have a significant inflection point. Further displacement increased the amount of the steel bars entering the plasticity stage at the beam end and the strain. At a displacement of $10 \mathrm{~mm}$, the steel bar strain at the end of the beam reached 0.0032, and the longitudinal reinforcement of the beam $100 \mathrm{~mm}$ from the edge of the column yielded. The force-displacement curve had a fairly obvious inflection point at this time. The "cusp point" indicated that the reinforced concrete at the beam end was fully yielded. After the joint yielded, the number of bending cracks on the beam no longer increased, and about six bending cracks were seen respectively in the left and right beams. These positive and negative bending cracks mutually interpenetrated one another, and some were staggered with the crack spacing between 100 and $180 \mathrm{~mm}$. The crack farthest from the edge of the column was $682 \mathrm{~mm}$ away and had a crack width of $0.38 \mathrm{~mm}$. The main crack was found at the beam end and had a crack width of $1.08 \mathrm{~mm}$. The development of 
this main crack and the yielding of the steel bar caused the bending cracks away from the edge of the column to develop slowly. This crack development indicates that the energy was mainly absorbed by the reinforced concrete in the main crack zone. Thus, the development of cracking and plasticity of reinforced concrete in other areas of the beam was delayed. The distribution of bending cracks in the beam when the joint was fully yielded is shown in Figure 8.

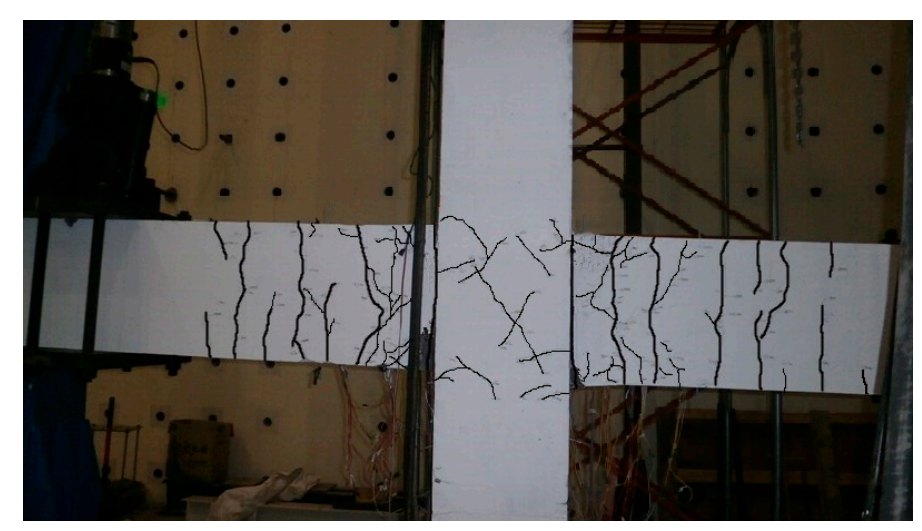

Figure 8. Distribution of cracks on the beam after yielding of the cast-in-place joint.

The strengthening phase occurred after the joint was yielded and displacement continued. When $\Delta=2 \Delta \mathrm{y}$, the width of the main crack on the beam at the edge of the column reached $2.86 \mathrm{~mm}$. At this time, the strain gauge of the beam reached its limit and lost measuring capability. When $\Delta=2.5 \Delta y$, small oblique cracks appeared on the periphery of the core area of the joint, and the concrete at the bottom and top of the beam were lifted due to the pressure and slightly enlarged. When $\Delta=4 \Delta y$, a main cross-diagonal crack appeared in the core area of the joint and had a width of $0.12 \mathrm{~mm}$. The width of the main crack at the beam end developed further and the bending crack on the beam saw no more significant growth. Further displacement caused the concrete at the bottom of the beam end to be repeatedly pressed and pulled, resulting in damage which caused concrete to drop from the beam that could be heard clearly. When $\Delta=5 \Delta y$, the concrete in the plastic hinge area of the beam was severely damaged, and the falling concrete had a particle size of up to $6 \mathrm{~mm}$. The amount of small oblique cracks in the core area of the joint increased, but development of the oblique crack in the column was not obvious. The instruments, such as the extensometer and the displacement meter, were removed to avoid damage due to the severe deformation of the joint. The concrete on the upper and lower parts of the beam end was removed by damage; thus, the beam end approached the condition of being a "rotating hinge" as the plastic hinge of the beam end developed. The final joint load dropped to $85 \%$ of the peak load, at which time the joint was considered to be broken, and the loading was stopped. The shape of the beam hinge area when the cast-in-place joint was broken is shown in Figure 9.

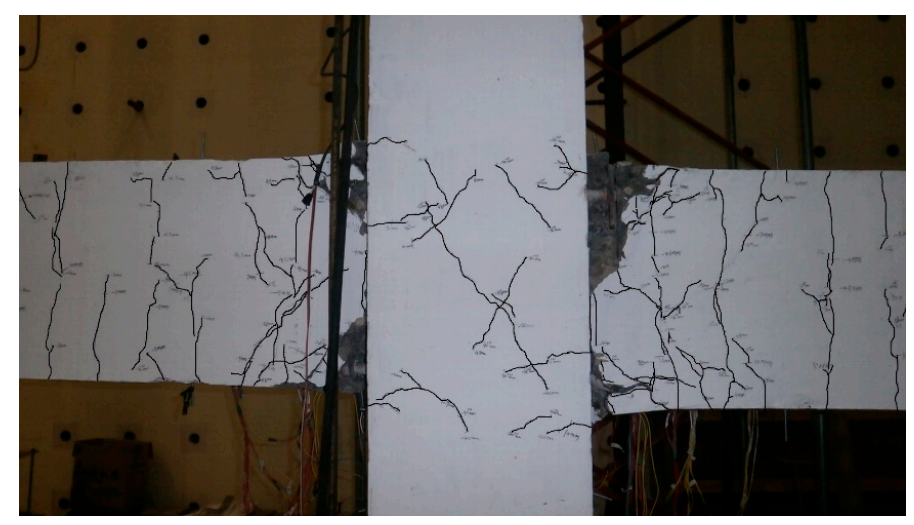

Figure 9. Final damage of cast-in-place joint. 


\subsection{Precast Prestressed Concrete Joints}

\subsubsection{PPCJ1}

The force-displacement curve of the PPCJ1 joint was linear before cracking of the specimen and the reciprocating curves in this portion of the test almost coincided with each other, showing that PPCJ1 exhibited elastic behavior. The first cracks appeared on the left and right beams when the loading displacement was $1.5 \mathrm{~mm}$ with crack widths of $0.06 \mathrm{~mm}$ and $0.07 \mathrm{~mm}$, respectively. The vertical new-old concrete interfaces in the keyway area of the left and right beams had vertical cracks that almost ran through the interface with crack widths of $0.04 \mathrm{~mm}$ and $0.05 \mathrm{~mm}$, respectively. There was no cracking at the end of the beam, indicating that the tensile strength of the vertical new-old concrete interface was lower than that of the cast concrete. The initial crack on the PPCJ1 beam is shown in Figure 10. When $\Delta=2 \mathrm{~mm}$, the crack at the vertical new-old concrete interface extended into the horizontal laminated layer, and the stiffness of the force-displacement curve decreased during forward loading.

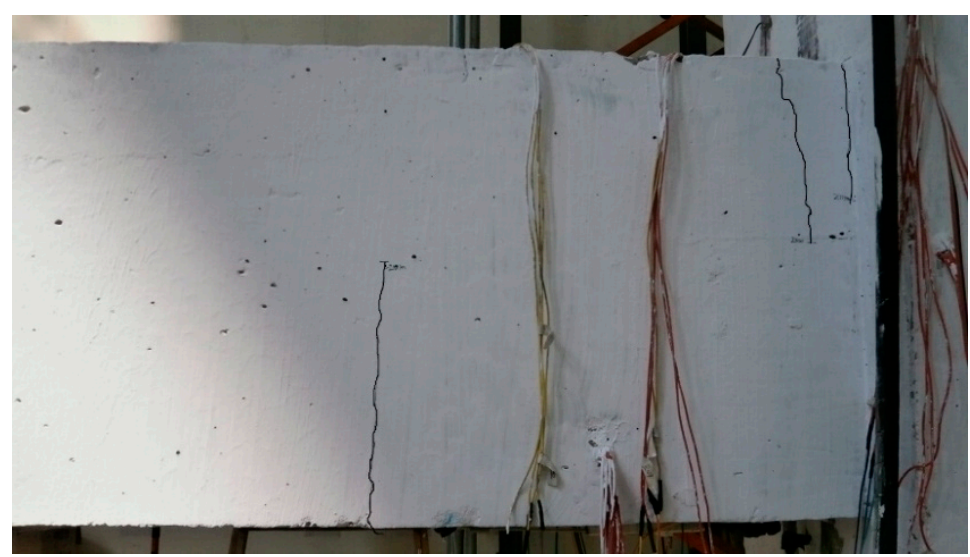

Figure 10. The initial cracking of the first precast prestressed concrete joint (PPCJ1).

The strain of tensile reinforcement at the beam end yielded when $\Delta=8 \mathrm{~mm}$. Thus, the yield displacement of the joint was considered to be $\Delta y=8 \mathrm{~mm}$. At this point, there were about five or six bending cracks in each of the upper and lower surfaces of the left and right beams. The crack distribution of the PPCJ1 joint at yielding is shown in Figure 11. The force-displacement curve clearly shows inflection points indicating that the beam end reinforced concrete had yielded. As loading continued, there was almost no development of the crack at the vertical interface in the keyway area, and the main crack at the end of the beam was widened and extended through the entire beam section. Although the crack at the vertical interface appeared first in the forward loading, the main crack in the precast prestressed concrete joint was found at the beam end near the edge of the column. This location was where bending shear cracks and compressive cracks were developed, and the deformation was the most serious. The crack at the vertical interface remained almost unchanged during the subsequent loading, and the crack width stayed at about $1.15 \mathrm{~mm}$. Oblique bending shear cracks appeared on the beam when $\Delta=2 \Delta y$ while the bending crack did not significantly develop. When $\Delta=3 \Delta y$, pressing on the bottom of the left beam caused damage of the concrete, indicating that the concrete reached the ultimate strength of compression. The next reverse loading caused concrete debris at the bottom of the beam to begin falling as loading shifted from compression to tension. The core of the joint showed the first diagonal crack with a right tilt and a crack width of $0.04 \mathrm{~mm}$. When $\Delta=4 \Delta \mathrm{y}$, a diagonal crack in the other direction appeared in the core area of the joint with a crack width of $0.09 \mathrm{~mm}$. The crack width of the main crack on the beam increased with further displacement. At $\Delta=5 \Delta y$, the joint deformation was serious, and the concrete bulging was obvious. The rate of concrete falling from the beam increased, and the concrete debris size reached up to $5.5 \mathrm{~mm}$. Further displacement 
caused the concrete on the upper and lower parts of the PPCJ1 beam to be removed, and the beam end approached a "rotating hinge" condition. This hinge behavior is similar to that observed in the cast-in-place joint discussed in Section 3.1. When $\Delta=8 \Delta y$, the joint load had fallen to $85 \%$ of the peak load; the joint was considered to be broken, and the loading was stopped. The final damage of the joint is shown in Figure 12. The concrete at the junction of the beam and the column was almost hollowed out, and the opening extended along the curved end of the prestressing tendon to form a gap of about $15 \mathrm{~mm}$ wide. The failure mode of PPCJ1 shows that plastic failure occurred at the beam end, resulting in a plastic hinge being formed. This failure mode of the PPCJ1 joint was similar to that of the cast-in-place joint.

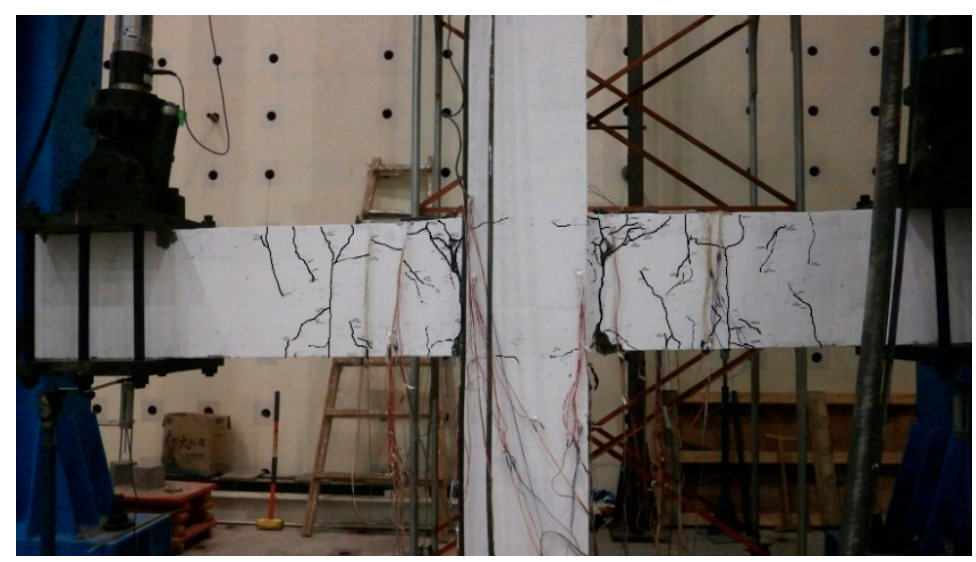

Figure 11. Distribution of cracks on the beam after yielding of the PPCJ1 joint.

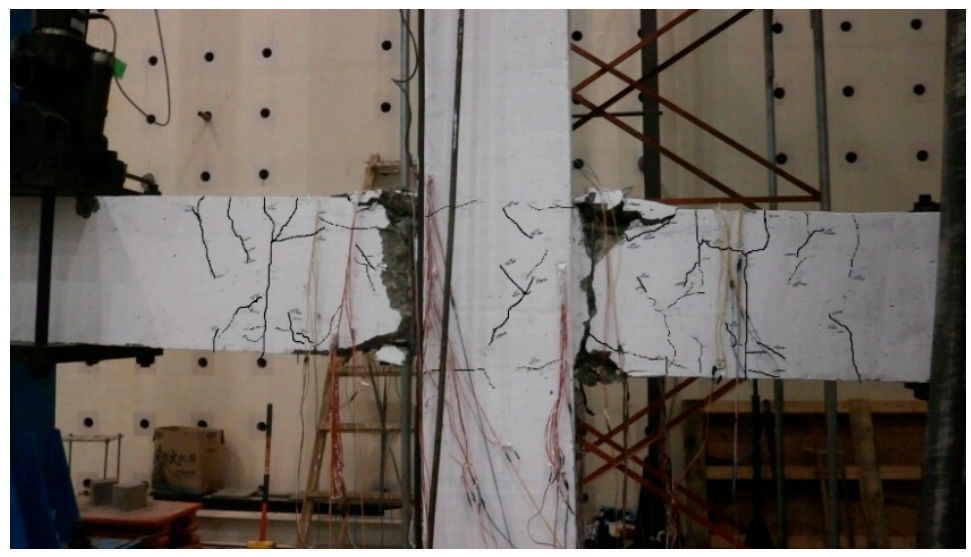

Figure 12. Final damage of the PPCJ1 joint.

\subsubsection{PPCJ2}

The behavior of PPCJ2 joint was similar to the PPCJ1 joint. At the loading displacement $\Delta=1.5 \mathrm{~mm}$, the first set of cracks appeared and are shown in Figure 13. When $\Delta=2 \mathrm{~mm}$, bending cracks were seen on the concrete-laminated layer on the upper side of the beam, and a second set of bending cracks developed between the vertical new-old concrete interface and the edge of the column. At $\Delta=8 \mathrm{~mm}$, the yield strain of tensile reinforcement at the beam end was reached; thus, $\Delta y=8 \mathrm{~mm}$. At this yielding displacement, the number of bending cracks on the beam no longer increased. The crack distribution of the PPCJ2 joint was relatively orderly when compared with the bending crack distribution of the PPCJ1 joint. In PPCJ2, the bending cracks at the bottom of the beam were mainly distributed in the keyway area. The main crack of the beam was the bending crack that was close to the edge of the column. The crack distribution of the PPCJ2 joint at yielding is shown in Figure 14. When $\Delta=10 \mathrm{~mm}$, all the tensile reinforcements at the beam end yielded, and 
the force-displacement curve showed an inflection point, indicating that the reinforced concrete at the end of the beam was fully yielded. When $\Delta=2 \Delta y$, the width of the main bending crack was $3.28 \mathrm{~mm}$, the crack width of the vertical new-old concrete interface was $0.95 \mathrm{~mm}$, and microcracks appeared in the concrete in the compression zone. When $\Delta=2.5 \Delta \mathrm{y}$, the width of the main crack on the beam had grown to $3.36 \mathrm{~mm}$, and the concrete under pressure at the bottom of the beam reached the ultimate strength of compression and was crushed. At this time, an oblique crack with a rightward inclination and a crack width of $0.06 \mathrm{~mm}$ in the core area of the joint was observed. At $\Delta=3 \Delta \mathrm{y}$, the crushing sound of the concrete under pressure was heard, and concrete debris dropped during the loading process. An oblique crack in the left direction appeared in the core area of the joint with a crack width of $0.15 \mathrm{~mm}$. Increasing the loading displacement caused the width of the main crack on the beam to grow. The concrete debris continued falling, and the debris had a diameter of up to $6.5 \mathrm{~mm}$. When $\Delta=5 \Delta y$, the joint deformation was severe, the concrete at the upper and lower ends of the beam were removed by the damage process, and the longitudinal reinforcements and stirrups at the bottom of the beam were exposed. As the loading continued, the concrete on the upper and lower parts of the PPCJ2 joint beam was removed, and the beam end approached a "rotating hinge" behavior. This is a similar behavior to what was observed in the other two joints. At $\Delta=8 \Delta \mathrm{y}$, the joint load dropped to $85 \%$ of the peak load; the joint was considered to be broken, and the test was stopped. The final damage of the joint is shown in Figure 15.

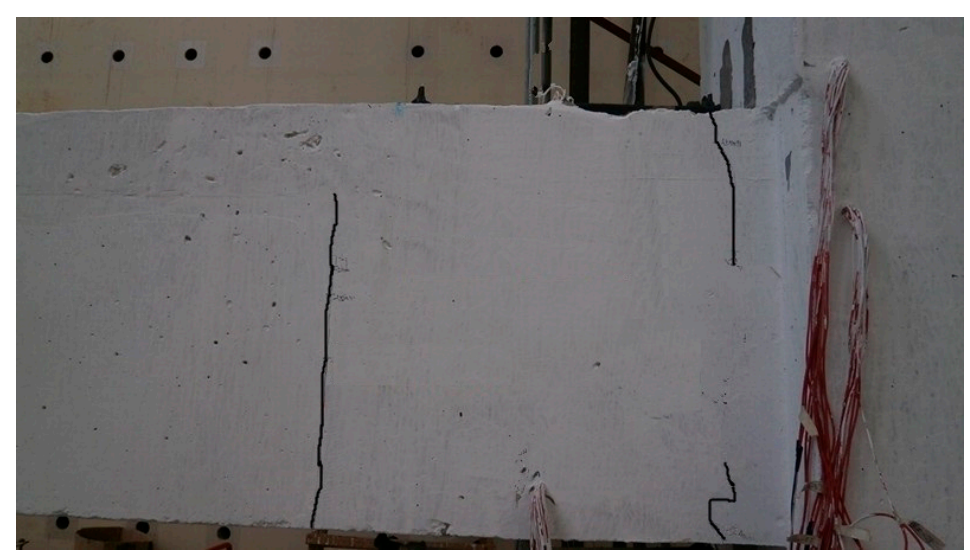

Figure 13. The initial cracking of PPCJ2 joint.

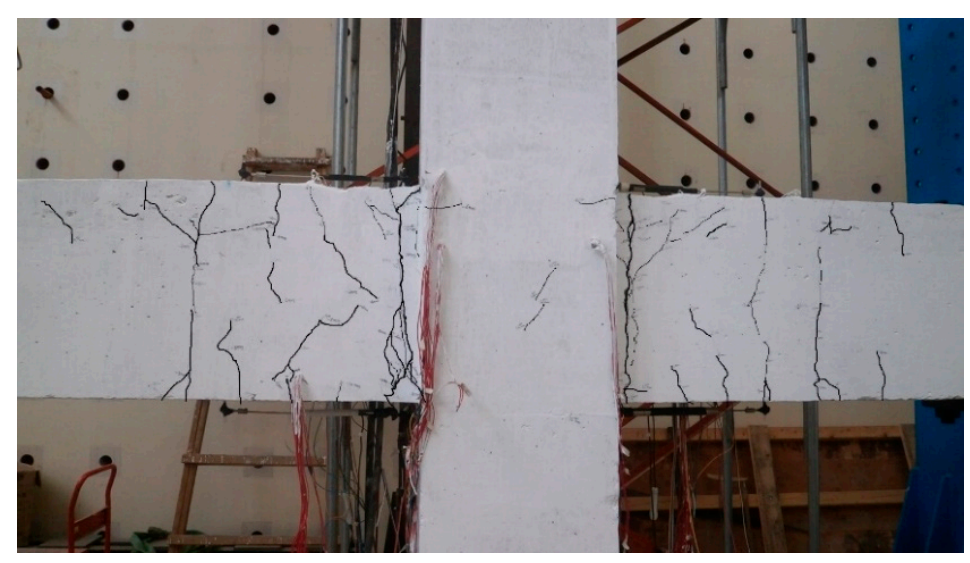

Figure 14. Distribution of cracks on the beam after yielding of the PPCJ2 joint. 


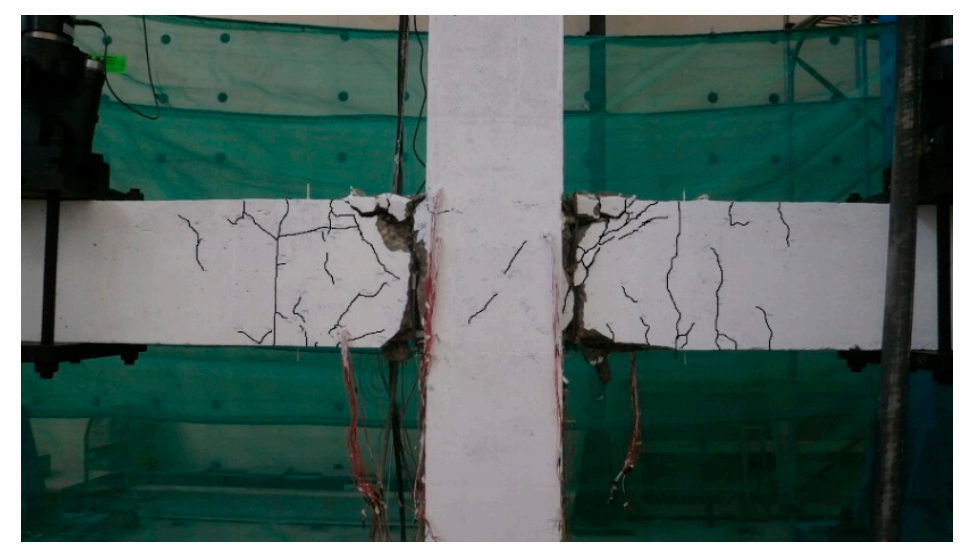

Figure 15. Final damage of the PPCJ2 joint.

In summary, cracking occurred slightly earlier in the precast prestressed concrete joints than in the cast-in-place joints. The bar lap connection in the keyway area did not change the position of the plastic hinge at the end of the beam. The development of the plastic hinge at the end of the precast prestressed concrete joint beam was the same as that of the cast-in-place joint. The bending cracks of the cast-in-place joints were more evenly distributed, while the cracks at the bottom of the precast prestressed concrete joints were mainly distributed in the keyway area. The cracks at the top of the beam of precast prestressed concrete joints were widely distributed, similar to the cast-in-place joints. The prestressing in the precast beam resulted in fewer cracks developing in the precast beam.

The first crack of the precast prestressed concrete joints appeared in the vertical new-old concrete interface of the keyway area. However, as the loading displacement increased, the vertical crack only developed several small cracks at its upper and lower ends, and the crack width grew slowly. The main crack on the beam was the same for the precast prestressed concrete joint and the cast-in-place joint, and it still appeared at the edge of the beam-column junction. The failure and damage of the concrete at the bottom of the precast prestressed concrete joint beam exposed the reinforcement at the bottom of the beam, and the effective area of the bar lap connection was continuously reduced. Thus, the lap connection effect of the beam hinge area was gradually weakened, and the stress of "double-layer steel bar" in the precast prestressed concrete joint was continuously transferred to the stress of "single-layer steel bar" of the cast-in-place joint.

No horizontal cracks were found in the horizontal laminated layer of the precast prestressed concrete joints during loading; this indicated that the "manual chiseling" method of the horizontal new-old concrete interface met the horizontal shearing requirements. The first bending crack appeared at the vertical new-old concrete interface of the keyway area, and this indicated that the cracking strength of the new-old concrete interface was weaker than that of the cast concrete. Except for the development of bending cracks along the vertical new-old concrete interface, there was no vertical slip along the interface of the concrete on both sides, and no oblique cracks appeared on both sides. The lack of vertical slip and oblique crack development indicated that the interface anti-shear method based on the "shear key" of the vertical new-old concrete interface achieved the shear resistance requirements for the test conditions. At the interface, there was no concrete crushing or bulging observed. Thus, the concrete at the junction of the new and old concrete met the pressure resistance requirements.

The development of several oblique cracks was observed in the core area during the loading, but no significant shear failure occurred. Therefore, the design of the precast prestressed concrete test joint met the requirements. The crack width no longer increased after the load exceeded the peak value due to the full development of the beam hinge that absorbed most of the energy and deformation of the joint. 


\section{Hysteresis Curve and Skeleton Curve}

The hysteresis curves of the three joints are shown in Figure 16. The hysteresis curves are smooth and full for all joints. At the initial stage of loading, the structures were in the elastic phase, and the forward and reverse loading curves of the hysteresis loops were almost coincident. The hysteresis curves showed nonlinearity when the joints became cracked, and the concrete was damaged. This nonlinearity was manifested by the phenomenon of non-coincidence of the loading and unloading curves and pinching of the hysteresis loops. The hysteresis loops were fusiform as the joints progressed from yielding until peak load. A "cusp" appeared in the hysteresis curves from the joint yielding to its complete yielding. These cusps were generally located between 8 and $10 \mathrm{~mm}$. At this cusp, the steel bars began yielding. However, there was a lack of consistency in this yielding due to uncertainties such as the construction of the joint, and the load had to be increased before the joint could be considered fully yielded. After the joints were fully yielded, the pinching phenomenon of the hysteresis loops was seen. The later hysteresis loops gradually develop toward the "anti-S shape", but the hysteresis loops remained full.
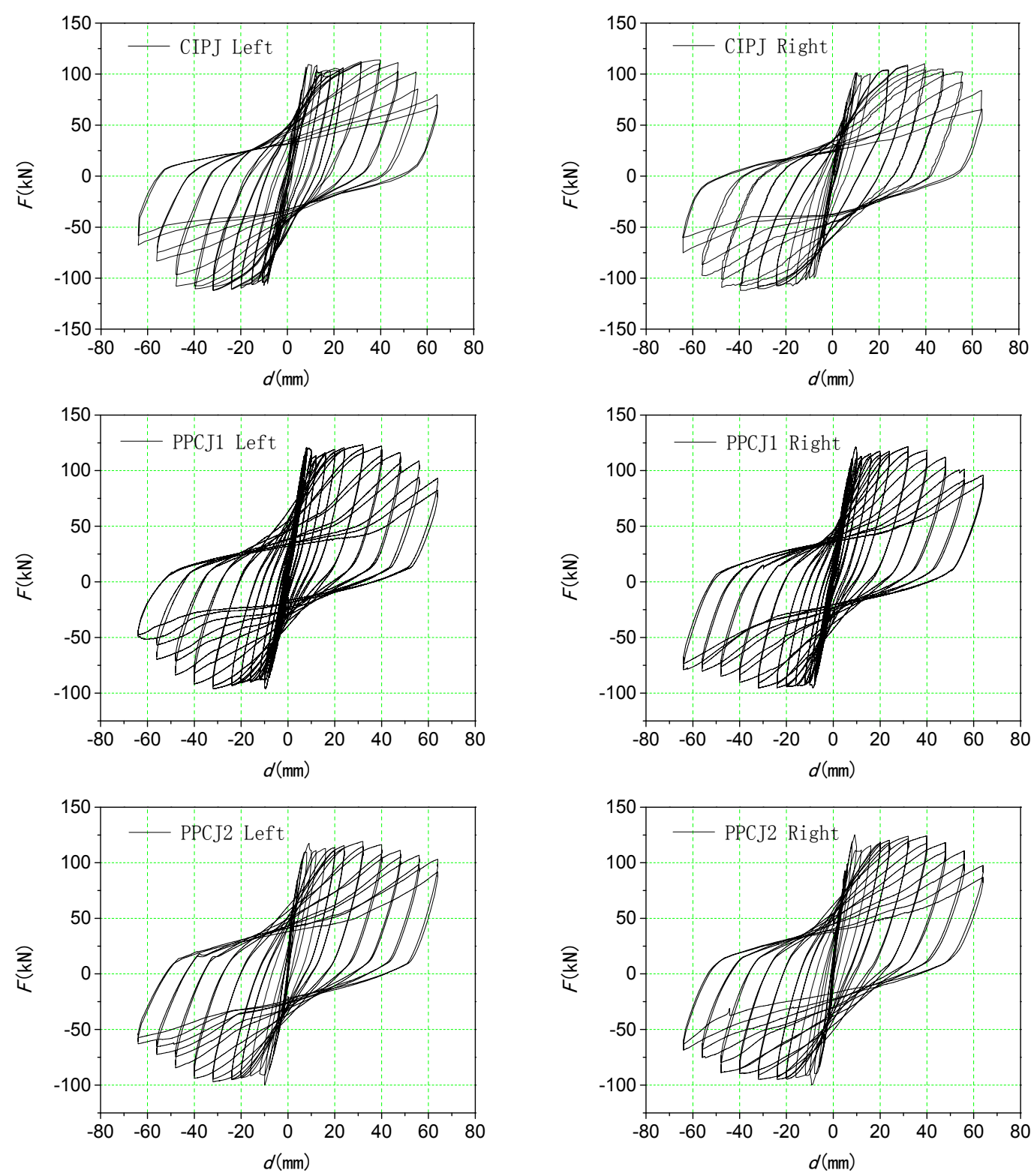

Figure 16. Hysteresis curves of the three joints. 
The skeleton curves of the three joints are shown in Figure 17. The cracking point is the position on the skeleton curve where the test specimen begins to crack. The yield point is commonly determined through the energy equivalence method and geometric mapping method. The skeleton curve of each joint has a clear inflection point; thus, the inflection point was used to determine the yield point. The corresponding force and displacement values were used as the component of the "limit point" when the load on the skeleton curve dropped to $85 \%$ of the peak value. The specific values of these parameters determined from the skeleton curves are listed in Table 3.

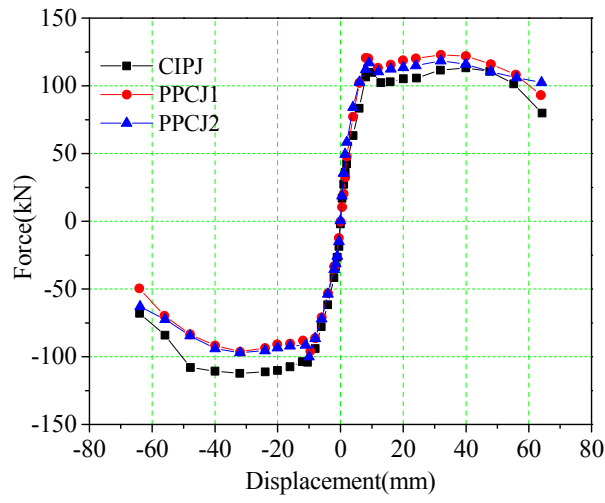

(a)

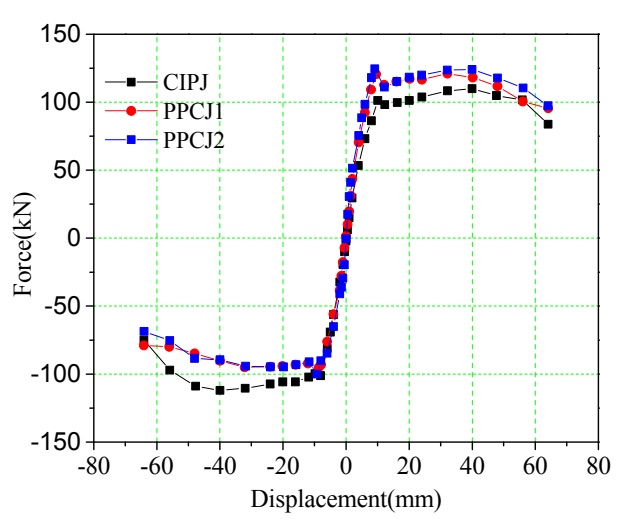

(b)

Figure 17. Comparison of joint skeleton curves: (a) left beam; (b) right beam.

Table 3. Parameters of joints from skeleton curves. CIPJ—cast-in-place joint.

\begin{tabular}{|c|c|c|c|c|c|c|c|c|c|c|c|}
\hline \multirow{2}{*}{ Joint } & \multirow{2}{*}{ Position } & \multicolumn{2}{|c|}{ Cracking Point } & \multicolumn{2}{|c|}{ Yield Point } & \multicolumn{2}{|c|}{ Peak Point } & \multicolumn{2}{|c|}{ Limit Point } & \multirow{2}{*}{$\begin{array}{l}\text { Ductility } \\
\text { Factor }\end{array}$} & \multirow{2}{*}{$\begin{array}{c}\text { Average } \\
\text { Ductility Factor }\end{array}$} \\
\hline & & $F(\mathrm{kN})$ & $d(\mathrm{~mm})$ & $F(\mathrm{kN})$ & $d(\mathrm{~mm})$ & $F(\mathrm{kN})$ & $d(\mathrm{~mm})$ & $F(\mathrm{kN})$ & $d(\mathrm{~mm})$ & & \\
\hline \multirow{2}{*}{ CIPJ } & $\begin{array}{c}\text { left } \\
\text { beam }\end{array}$ & $\begin{array}{c}42.53 \\
-41.01\end{array}$ & $\begin{array}{c}2.0 \\
-2.0\end{array}$ & $\begin{array}{c}110.00 \\
-104.14\end{array}$ & $\begin{array}{c}10.0 \\
-10.5\end{array}$ & $\begin{array}{c}113.31 \\
-112.23\end{array}$ & $\begin{array}{c}39.9 \\
-32.1\end{array}$ & $\begin{array}{c}96.31 \\
-95.40\end{array}$ & $\begin{array}{c}57.4 \\
-52.1\end{array}$ & $\begin{array}{l}5.66 \\
5.10\end{array}$ & 5.38 \\
\hline & $\begin{array}{l}\text { right } \\
\text { beam }\end{array}$ & $\begin{array}{c}30.86 \\
-32.64\end{array}$ & $\begin{array}{c}2.0 \\
-2.0\end{array}$ & $\begin{array}{c}101.20 \\
-101.20\end{array}$ & $\begin{array}{l}10.1 \\
-8.1\end{array}$ & $\begin{array}{c}109.93 \\
-111.99\end{array}$ & $\begin{array}{c}39.9 \\
-39.9\end{array}$ & $\begin{array}{c}93.44 \\
-95.19\end{array}$ & $\begin{array}{c}59.6 \\
-56.6\end{array}$ & $\begin{array}{l}6.22 \\
6.24\end{array}$ & 6.23 \\
\hline \multirow{2}{*}{ PPCJ1 } & $\begin{array}{c}\text { left } \\
\text { beam }\end{array}$ & $\begin{array}{c}32.12 \\
-33.19\end{array}$ & $\begin{array}{c}1.5 \\
-1.5\end{array}$ & $\begin{array}{c}120.18 \\
-95.87\end{array}$ & $\begin{array}{c}8.9 \\
-9.6\end{array}$ & $\begin{array}{l}122.94 \\
-96.33\end{array}$ & $\begin{array}{c}32.0 \\
-32.0\end{array}$ & $\begin{array}{c}104.50 \\
-81.88\end{array}$ & $\begin{array}{c}57.9 \\
-48.9\end{array}$ & $\begin{array}{l}6.52 \\
5.10\end{array}$ & 5.81 \\
\hline & $\begin{array}{l}\text { right } \\
\text { beam }\end{array}$ & $\begin{array}{c}31.28 \\
-28.58\end{array}$ & $\begin{array}{c}1.5 \\
-1.5\end{array}$ & $\begin{array}{l}120.54 \\
-95.11\end{array}$ & $\begin{array}{c}9.6 \\
-8.6\end{array}$ & $\begin{array}{l}121.03 \\
-95.11\end{array}$ & $\begin{array}{c}32.1 \\
-32.1\end{array}$ & $\begin{array}{l}102.87 \\
-80.84\end{array}$ & $\begin{array}{c}54.3 \\
-54.6\end{array}$ & $\begin{array}{l}5.71 \\
6.34\end{array}$ & 6.03 \\
\hline \multirow{2}{*}{ PPCJ2 } & $\begin{array}{c}\text { left } \\
\text { beam }\end{array}$ & $\begin{array}{c}49.75 \\
-31.46 \\
\end{array}$ & $\begin{array}{c}1.5 \\
-1.5 \\
\end{array}$ & $\begin{array}{c}117.00 \\
-100.00\end{array}$ & $\begin{array}{c}9.1 \\
-10.0\end{array}$ & $\begin{array}{l}118.50 \\
-97.00\end{array}$ & $\begin{array}{c}32.0 \\
-32.0\end{array}$ & $\begin{array}{l}100.73 \\
-82.45\end{array}$ & $\begin{array}{c}68.1 \\
-49.3\end{array}$ & $\begin{array}{l}7.05 \\
4.93\end{array}$ & 5.99 \\
\hline & $\begin{array}{l}\text { right } \\
\text { beam }\end{array}$ & $\begin{array}{c}41.00 \\
-36.08\end{array}$ & $\begin{array}{c}1.5 \\
-1.5\end{array}$ & $\begin{array}{c}124.59 \\
-100.00\end{array}$ & $\begin{array}{c}9.1 \\
-9.2\end{array}$ & $\begin{array}{c}124.08 \\
-94.24\end{array}$ & $\begin{array}{c}39.9 \\
-31.8\end{array}$ & $\begin{array}{l}105.47 \\
-80.10\end{array}$ & $\begin{array}{c}59.2 \\
-50.3\end{array}$ & $\begin{array}{l}6.15 \\
5.76\end{array}$ & 5.96 \\
\hline
\end{tabular}

It can be seen from Figures 16 and 17, and Table 3 that the cracking displacements of the cast-in-place joint and the precast prestressed concrete joint were different. However, the cracking loads were typically between $31 \mathrm{kN}$ and $42 \mathrm{kN}$. Generally, the cracking load during forward loading was greater than that during reverse loading. The yield displacement of each joint was relatively close and was about $8-10 \mathrm{~mm}$. The yield point behavior was evident for all joints. The yield, peak, and limit displacements and loads of the two precast prestressed concrete joints were relatively close in both directions, though the load during forward loading was greater than that during reverse loading. The yield, peak, and limit loads of the precast prestressed concrete joint during forward loading were greater than that of the cast-in-place joint, while the loads during reverse loading were smaller than that of the cast-in-place joint. This was because reinforcements of the precast prestressed concrete joints overlap at the beam end, and the effective reinforcement ratio of the beam bottom was improved. Asymmetry of the plastic zone of the beam section was formed since the reinforcement ratio of the beam top was the same as that of the cast-in-place joint. This asymmetry caused greater resistance during forward loading and lower resistance during reverse loading. 


\section{Stiffness and Bearing Capacity Degradation}

The development of concrete cracks and the accumulation of plastic damage during the loading degrade the mechanical properties, such as stiffness and strength, of the joints, thus affecting the ductility and energy dissipation of the joints.

\subsection{Stiffness Degradation}

Stiffness degradation is the phenomenon where the peak displacement increases with the number of loading cycles under the same peak load. Here, the loop stiffness is used to describe the stiffness degradation, and the loop stiffness is calculated as follows:

$$
K_{j}=\frac{\sum_{i=1}^{n} P_{j, i}}{n \mu_{j}},
$$

where $K_{j}$ is the average loop stiffness of the joint in the $j$ th loading stage; $\mu_{j}$ is the displacement amplitude in the $j$ th loading stage; $n$ is the number of loading cycles under the same displacement amplitude; $P_{j, i}$ is the peak load in the $i$ th cycle at the $j$ th displacement.

The relationship between the loop stiffness and the loading displacement of the left and right beams of each joint is shown in Figures 18 and 19. The stiffness degradation of the three joints is seen to be similar from these figures. The rate of stiffness degradation was faster in the early stage of loading, and the stiffness degradation mainly occurred in the cracking and yielding stages. Stiffness was reduced as the cracks in the concrete expanded, and the yielding of the steel bar occurred. After the peak load, the pressed concrete on the beam was crushed, and a "plastic hinge" at the end of the beam developed, causing a low rate of stiffness degradation with further displacement. The variation of the loop stiffness during the forward and reverse loading of the left and right beams of the cast-in-place joint was almost symmetrical. However, the loop stiffness of precast prestressed concrete joints PPCJ1 and PPCJ2 in forward loading was greater than that in reverse loading. The loop stiffness values in the forward and reverse loading approach as the loading displacement reached the peak load displacement of $32 \mathrm{~mm}$.

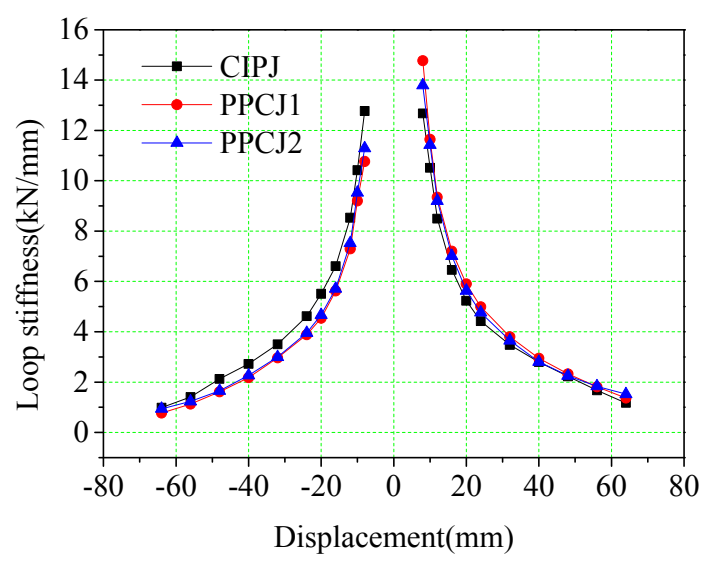

Figure 18. Relationship between loop stiffness and displacement of the joint left beam.

The loop stiffnesses of the precast prestressed concrete joints PPCJ1 and PPCJ2 were greater than that of the cast-in-place joint during forward loading. The loop stiffness during reverse loading of PPCJ1 and PPCJ2 was smaller than the cast-in-place joint. After peak loads, the loop stiffnesses became similar for PPCJ and CIPJ. These values approached because the reinforcement overlapping at the bottom of the keyway area increased the effective reinforcement ratio of the longitudinal reinforcement at the bottom of the beam, while the beam top reinforcement was the same as the cast-in-place joint. Increasing the loading displacement beyond yielding caused further cracking of the beam 
and concrete damage, and the force transmission of the overlapped reinforcements was weakened. At peak load, the concrete in the plastic hinge area of the precast prestressed concrete joint was severely damaged, and the U-shaped steel bars and prestressing tendons in the overlap area were exposed. The overlapped reinforcements could only anchor in the undamaged area of the concrete at the end of the beam. Consequently, only the U-shaped steel bars were effectively transmitting force. Thus, the force transmission at the beam ends for PPJC1 and PPJC2 at near peak load were consistent with the cast-in-place joint.

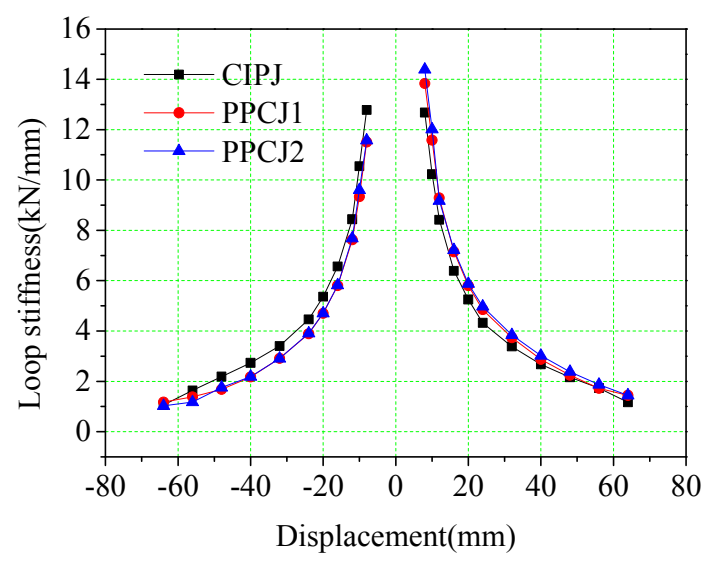

Figure 19. Relationship between loop stiffness and displacement of the joint right beam.

The joints PPCJ1 and PPCJ2 had similar loop stiffness during forward loading except when just yielding. For reverse loading, the loop stiffness of PPCJ2 was slightly larger than that of PPCJ1. This difference was because the joints only had concrete of different strengths in the keyway area of the beam. The concrete of the beam top was the same for PPCJ1 and PPCJ2. During forward loading, the concrete of the beam bottom was pulled in tension and the cracks appeared earlier. In this case, the main contribution to the stiffness was the bottom reinforcement and top concrete of the beam. Thus, the stiffness was similar in forward loading for PPCJ1 and PPCJ2. For reverse loading, the bottom of the keyway area was pressed compressively, and the concrete at the bottom of the beam played a significant role in determining stiffness. Therefore, the loop stiffness was greater for PPCJ2 since it used a higher strength concrete. However, the contribution to loop stiffness of the joint was limited.

\subsection{Bearing Capacity Degradation}

The bearing capacity degradation is the phenomenon that the peak load decreases with the increase in the number of loading cycles under the same loading displacement amplitude. The bearing capacity degradation coefficient is calculated according to

$$
\alpha=\frac{P_{j, n}}{P_{j, 1}}
$$

where $\alpha$ is the bearing capacity degradation coefficient; $P_{j, n}$ is the peak load in the $n$th loading cycle when the displacement amplitude is $\mu_{j} ; P_{j, 1}$ is the peak load in the first loading cycle when the displacement amplitude is $\mu_{j}$.

The relationship between the bearing capacity degradation coefficient and the displacement for each joint is shown in Figures 20 and 21. These figures show that a yielding platform occurred when the joint first started yielding, and the bearing capacity degradation coefficient first dropped, and then rose. The steel bar in the beam entered the strengthening stage when the joint was fully yielded, and the joint plasticity developed normally as the stress increased gradually. In this phase, the bearing capacity degradation coefficient decreased. At the later stage of loading, the damaged concrete at 
the end of the beam fell off, new concrete became in contact with the column, the plasticity began developing again, and the bearing capacity degradation coefficient increased.

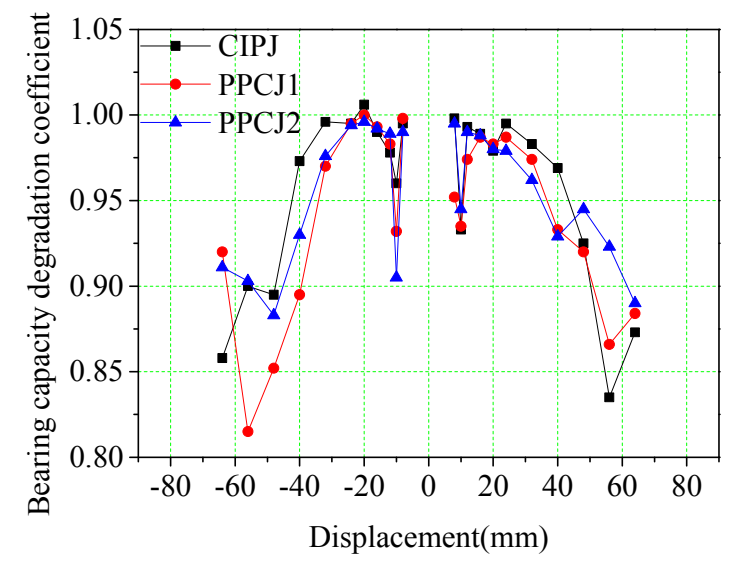

Figure 20. Bearing capacity degradation coefficient for left beam of joint.

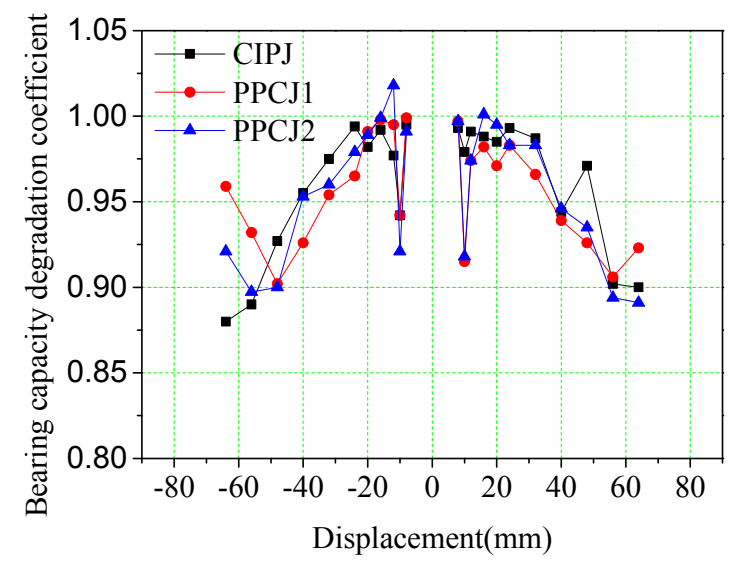

Figure 21. Bearing capacity degradation coefficient for right beam of joint.

The bearing capacity degradation coefficient of the cast-in-place joint was slightly larger than that of the precast prestressed concrete joints. This difference was because the bearing capacity degradation coefficient was related to the development of plasticity. The plasticity of the cast-in-place joint developed symmetrically, while the plasticity of the precast prestressed concrete joint developed asymmetrically and it entered the plastic stage quickly upon loading; thus, the bearing capacity of the precast prestressed concrete joint degenerated slightly faster than the cast-in-place joint. The bearing capacity degradation coefficient of PPCJ2 was generally slightly larger than that of PPCJ1. This larger value indicates that the increase of concrete strength in the keyway area slightly reduced the bearing capacity degradation of the precast prestressed concrete joint.

\section{Ductility and Energy Dissipation}

Ductility refers to the ability of a structure to withstand inelastic deformation without significant reduction in its bearing capacity after the structure enters plasticity. Ductility is related to the energy dissipation capacity of the structure. The ductility of a joint can be expressed by the displacement ductility coefficient of the beam at the loading end. This coefficient is calculated as follows:

$$
\mu=\frac{\Delta_{u}}{\Delta_{y}}
$$


where $\mu$ is the ductility coefficient of the joint; $\Delta_{u}$ is the ultimate displacement of the joint when it is broken, generally taken as the corresponding displacement when the bearing capacity of the joint drops to $85 \%$ of the peak load; $\Delta_{y}$ is the yield displacement of the joint.

The ductility coefficients of the three joints are shown in the two rightmost columns of Table 3. The ductility coefficients of the three joints were similar, and it can be considered that the three joints had considerable ductility. The different strength of concrete in the keyway area had little influence on the ductility as seen by comparing the precast prestressed concrete joints. The ductility coefficient for each joint was between 5.3 and 6.3, and these values are greater than the ductility coefficient of 3-4 as required for seismic structure design. Thus, the joints tested have good ductility and meet the structural seismic requirements.

Energy dissipation is an important indicator of the seismic performance of a structure. The equivalent viscosity damping coefficient is used to describe the energy dissipation capacity of a test joint under different loading displacements. A larger equivalent viscosity damping coefficient correlates with greater energy dissipation. The calculated values of the equivalent viscous damping coefficients of the three joints are listed in Table 4 and are calculated according to

$$
h_{e}=\frac{1}{2 \pi} \cdot \frac{A_{1}}{A_{2}+A_{3}}
$$

where $h_{e}$ is the equivalent viscous damping coefficient; $A_{1}$ is the area of the hysteresis loop BFDE in Figure 22; $A_{2}$ is the area of the triangle OAB in Figure 22; $A_{3}$ is the area of the triangle OCD in Figure 22. There average is taken when there are multiple cycles of the same level of loading displacement.

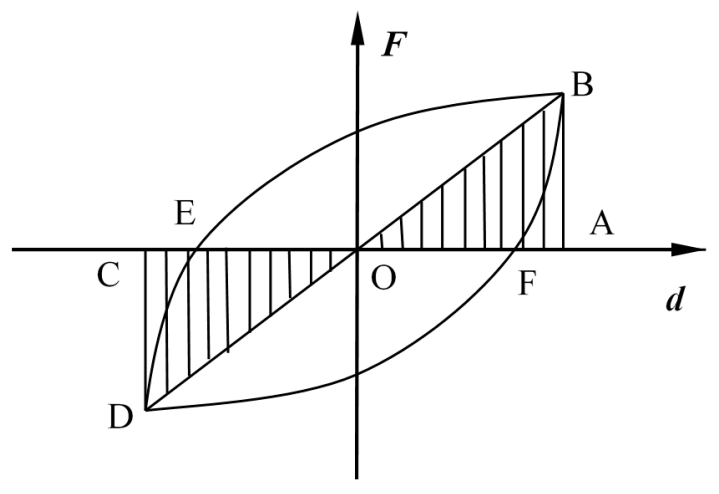

Figure 22. Schematic diagram of calculation for the equivalent viscosity damping coefficient.

At the start of yielding, the equivalent viscous damping coefficient of each joint increased with the loading displacement. As yielding began, the plasticity of the beam developed rapidly, and the energy dissipation increased. The equivalent viscous damping coefficient had only slight fluctuations in the displacement from $20 \mathrm{~mm}$ to the peak displacement. The local damage of concrete lowered the energy dissipation beyond $20 \mathrm{~mm}$ of displacement. However, the plasticity of the joint had room for development. The plasticity development and concrete damage were in a dynamic equilibrium that caused this stable portion of the coefficient. The coefficient tended to decrease slowly after the peak load was reached. After the peak load, part of the concrete was destroyed, and the energy dissipation of the joint was reduced.

The average value of the equivalent viscous damping coefficient for the cast-in-place joint at peak load was 0.2413 . The average viscous damping coefficients at peak load of the precast prestressed concrete joints PPCJ1 and PPCJ2 were 0.2340 and 0.2470 , respectively. The equivalent viscous damping coefficient was close for all joints. This similarity indicates that the energy dissipation capacity of the precast prestressed concrete joint was similar to that of the cast-in-place joint. Thus, the precast prestressed concrete joint had the same energy dissipation as the equivalent monolithic system. 
Table 4. Equivalent viscous damping coefficients of the test joints.

\begin{tabular}{ccccccc}
\hline \multirow{2}{*}{$\begin{array}{c}\text { Loading } \\
\text { Displacement (mm) }\end{array}$} & \multicolumn{2}{c}{ CIPJ } & \multicolumn{2}{c}{ PPCJ1 } & \multicolumn{2}{c}{ PPCJ2 } \\
\cline { 2 - 6 } & Left Beam & Right Beam & Left Beam & Right Beam & Left Beam & Right Beam \\
\hline 8 & 0.0472 & 0.0480 & 0.0421 & 0.0441 & 0.0778 & 0.0882 \\
12 & 0.0928 & 0.1070 & 0.1092 & 0.1105 & 0.1142 & 0.1270 \\
16 & 0.1622 & 0.1602 & 0.1389 & 0.1351 & 0.1697 & 0.1714 \\
20 & 0.2553 & 0.2227 & 0.2027 & 0.1697 & 0.1908 & 0.2009 \\
24 & 0.2420 & 0.1973 & 0.2144 & 0.2032 & 0.2076 & 0.2220 \\
32 & 0.2264 & 0.2351 & 0.2428 & 0.2253 & 0.2419 & 0.2520 \\
40 & 0.2372 & 0.2454 & 0.2361 & 0.2282 & 0.2418 & 0.2509 \\
48 & 0.2347 & 0.2450 & 0.2205 & 0.2120 & 0.2330 & 0.2410 \\
56 & 0.2315 & 0.2241 & 0.2045 & 0.2234 & 0.2266 & 0.2282 \\
64 & 0.2216 & 0.2171 & 0.2024 & 0.2082 & 0.2280 & 0.2208 \\
\hline
\end{tabular}

The actual energy dissipation capacity of the joints was compared using the cumulative energy dissipation index. The actual energy dissipation is the accumulated value of the envelope area $A_{1}$ of the hysteresis loop corresponding for each loading displacement. The accumulated value $\Delta a$ of the corresponding displacement is determined and is normalized by the yield displacement $\Delta y$. Relationships between cumulative energy dissipation and cumulative relative displacement of each joint for the left and right beams are shown in Figures 23 and 24.

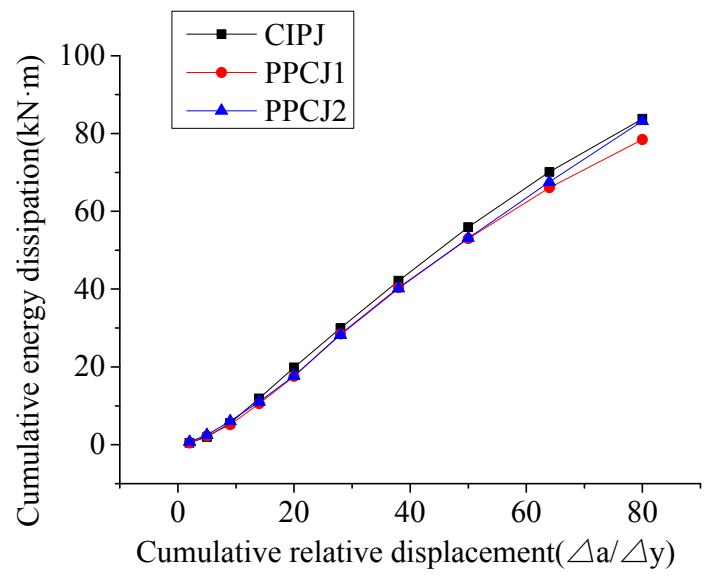

Figure 23. Relationship between cumulative energy dissipation and cumulative relative displacement of the joint left beam.

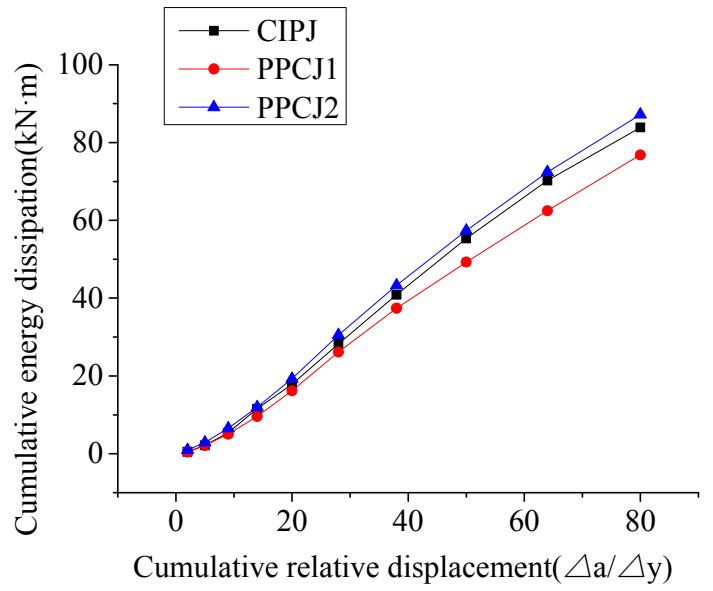

Figure 24. Relationship between cumulative energy dissipation and cumulative relative displacement of the joint right beam. 
Figures 23 and 24 show that the difference of cumulative energy dissipation between the left beam of the cast-in-place joint and the precast prestressed concrete joint was small and that the cumulative energy dissipation of the right beam of the PPCJ1 joint was slightly smaller than the other two joints. The cumulative energy dissipation of the PPCJ2 joint was slightly larger than that of the PPCJ1 joint. The energy dissipation of the right beam of the PPCJ2 joint was significantly larger than that of the PPCJ1 joint and was even larger than the cast-in-place joint. This difference may be due to the inconsistency in the construction. However, the cumulative energy dissipation of each joint was approximately linear. Thus, the energy dissipation capacity of each joint was uniform with the displacement, and the joint energy dissipation was stable.

\section{Conclusions}

In this paper, reversed cyclic loading tests were carried out on precast prestressed concrete joints and a cast-in-place joint. The conclusions are as follows:

(1) The failure modes of the three joints were beam end failure, and plastic hinges were observed at the beam ends. The core area of the joints was never destroyed; this satisfies the joint design principle of "strong joint weak component".

(2) The first crack of the precast prestressed concrete joint at the beam bottom occurred at the vertical new-old concrete interface. The largest bending crack and plastic hinge appeared at the beam end. Fewer cracks developed in the precast beam due to the prestress. The "manual chiseling" method for the horizontal new-old concrete interface and the "shear key" method for the vertical new-old concrete interface in the keyway area satisfied the shear resistance requirements of the member.

(3) The precast prestressed concrete joints were connected by overlapped steel bars in the keyway area. Thus, the load during the forward loading of the joint was increased, while the load during the reverse loading was reduced compared to the cast-in-place joint. The overlapped steel bars in the keyway area were well anchored and could meet the force transmission requirements of the precast prestressed concrete joints under cyclic loading.

(4) Concrete with different strengths in the keyway area affected the stiffness, load, ductility, and energy dissipation of the precast prestressed concrete joints. However, the effect was not strong for these parameters.

(5) The analysis of the hysteresis curves and skeleton curves showed that the precast prestressed concrete joint had comparable seismic resistance to the cast-in-place joint.

Author Contributions: Conceptualization, X.Y. and S.W. Formal analysis, S.W. Investigation, C.H. (Canling Huang). Project administration, X.Y. Supervision, A.Q. Visualization, C.H. (Chao Hong). Writing-original draft, C.H. (Canling Huang). Writing-review and editing, X.Y. and S.W.

Funding: This research was funded by the National Natural Science Foundation of China, grant number 51578160, the Science and Technology Project of Fujian Education Department, grant number JA15050, and the Fujian Science and Technology Plan Project, grant number 2018 Y0057.

Conflicts of Interest: The authors declare no conflicts of interest.

\section{References}

1. Maya, L.F.; Zanuy, C.; Albajar, L.; Lopez, C.; Portabella, J. Experimental assessment of connections for precast concrete frames using ultra high performance fibre reinforced concrete. Constr. Build. Mater. 2013, 48, 173-186. [CrossRef]

2. Liu, H.; Yan, Q.; Du, X. Seismic performance comparison between precast beam joints and cast-in-place beam joints. Adv. Struct. Eng. 2017, 20, 1299-1314. [CrossRef]

3. Lee, H.J.; Chen, H.C.; Syu, J.H. Seismic performance of emulative precast concrete beam-column connections with alternative reinforcing details. Adv. Struct. Eng. 2017, 20, 1793-1806. [CrossRef]

4. Choi, H.K.; Choi, Y.C.; Choi, C.S. Development and testing of precast concrete beam-to-column connections. Eng. Struct. 2013, 56, 1820-1835. [CrossRef] 
5. Lu, C.; Dong, B.; Pan, J.; Shan, Q.; Hanif, A.; Yin, W. An investigation on the behavior of a new connection for precast structures under reverse cyclic loading. Eng. Struct. 2018, 169, 131-140. [CrossRef]

6. Yang, K.H.; Seo, E.A.; Hong, S.H. Cyclic flexural tests of hybrid steel-precast concrete beams with simple connection elements. Eng. Struct. 2016, 118, 344-356. [CrossRef]

7. Ersoy, U.; Tankut, T. Precast concrete members with welded plate connections under reversed cyclic loading. PCI J. 1993, 38, 94-100. [CrossRef]

8. Aninthaneni, P.K.; Dhakal, R.P.; Marshall, J.; Bothara, J. Nonlinear cyclic behaviour of precast concrete frame sub-assemblies with "dry" end plate connection. Structures 2018, 14, 124-136. [CrossRef]

9. Shufeng, L.; Qingning, L.; Hao, Z.; Haotian, J.; Lei, Y.; Weishan, J. Experimental study of a fabricated confined concrete beam-to-column connection with end-plates. Constr. Build. Mater. 2018, 158, 208-216. [CrossRef]

10. Ketiyot, R.; Hansapinyo, C. Seismic performance of interior precast concrete beam-column connections with T-section steel inserts under cyclic loading. Earthq. Eng. Eng. Vib. 2018, 17, 355-369. [CrossRef]

11. Kim, J.H.; Cho, Y.S.; Lee, K.H. Structural performance evaluation of circular steel bands for PC column-beam connection. Mag. Concr. Res. 2013, 65, 1377-1384. [CrossRef]

12. Wu, Y.; Xiao, Y.; Anderson, J.C. Seismic behavior of PC column and steel beam composite moment frame with posttensioned connection. J. Struct. Eng. 2009, 135, 1398-1407. [CrossRef]

13. Yekrangnia, M.; Taheri, A.; Zahrai, S.M. Experimental and numerical evaluation of proposed precast concrete connections. Struct. Concr. 2016, 17, 959-971. [CrossRef]

14. Englekirk, R.E. Development and testing of a ductile connector for assembling precast concrete beams and columns. PCI J. 1995, 40, 36-51. [CrossRef]

15. Ozturan, T.; Ozden, S.; Ertas, O. Ductile connections in precast concrete moment resisting frames. PCI J. 2006, 51, 66-76. [CrossRef]

16. Vidjeapriya, R.; Jaya, K.P. Experimental study on two simple mechanical precast beam-column connections under reverse cyclic loading. J. Perform. Constr. Facil. 2012, 27, 402-414. [CrossRef]

17. Naik, C.B.; Joshi, D.D.; Patel, P.V. Experimental evaluation of performance of dry precast beam column connection. In Advances in Structural Engineering; Matsagar, V., Ed.; Springer: New Delhi, India, 2015; pp. 2333-2342.

18. Priestley, M.N.; Tao, J.R. Seismic response of precast prestressed concrete frames with partially debonded tendons. PCI J. 1993, 38, 58-69. [CrossRef]

19. Cheok, G.S.; Stone, W.C.; Kunnath, S.K. Seismic response of precast concrete frames with hybrid connections. Struct. J. 1998, 95, 527-539. [CrossRef]

20. Wang, H.; Marino, E.M.; Pan, P.; Liu, H.; Nie, X. Experimental study of a novel precast prestressed reinforced concrete beam-to-column joint. Eng. Struct. 2018, 156, 68-81. [CrossRef]

21. Morgen, B.G.; Kurama, Y.C. Seismic design of friction-damped precast concrete frame structures. J. Struct. Eng. 2007, 133, 1501-1511. [CrossRef]

22. Song, L.L.; Guo, T.; Chen, C. Experimental and numerical study of a self-centering prestressed concrete moment resisting frame connection with bolted web friction devices. Earthq. Eng. Struct. Dyn. 2014, 43, 529-545. [CrossRef]

23. Rodgers, G.W.; Solberg, K.M.; Mander, J.B.; Chase, J.G.; Bradley, B.A.; Dhakal, R.P. High-force-to-volume seismic dissipators embedded in a jointed precast concrete frame. J. Struct. Eng. 2010, 138, 375-386. [CrossRef]

24. Kaya, M.; Arslan, A.S. Analytical modeling of post-tensioned precast beam-to-column connections. Mater. Des. 2009, 30, 3802-3811. [CrossRef]

25. Liu, B.; Song, M.; Jiang, Y.; Huang, S.; Zhou, A. Experimental study on seismic performance of post-tensioned precast prestressed concrete frame. J. Build. Struct. 2011, 32, 24-32. [CrossRef]

26. Zhong, X.; Meng, S.; Pan, Q. Experimental study on seismic performance of post-tensioned prestressed precast concrete beam-column assemblages. China Civ. Eng. J. 2012, 45, 38-44. [CrossRef]

27. Ha, S.S.; Kim, S.H.; Lee, M.S.; Moon, J.H. Performance evaluation of semi precast concrete beam-column connections with U-shaped strands. Adv. Struct. Eng. 2014, 17, 1585-1600. [CrossRef]

28. Cai, J.; Zhu, H.; Feng, J.; Liu, Y.F.; Huang, L.F. Experimental study on seismic behavior of middle joints of SCOPE system. J. Central South Univ. (Sci. Technol.) 2012, 43, 305-312.

29. Liu, Y.; Cai, J.; Deng, X.; Cao, Y.; Feng, J. Experimental study on effect of length of service hole on seismic behavior of exterior precast beam-column connections. Struct. Concr. 2018, 1-12. [CrossRef] 
30. Guan, D.; Guo, Z.; Xiao, Q.; Zheng, Y. Experimental study of a new beam-to-column connection for precast concrete frames under reversal cyclic loading. Adv. Struct. Eng. 2016, 19, 529-545. [CrossRef]

31. Parastesh, H.; Hajirasouliha, I.; Ramezani, R. A new ductile moment-resisting connection for precast concrete frames in seismic regions: An experimental investigation. Eng. Struct. 2014, 70, 144-157. [CrossRef]

32. Im, H.J.; Park, H.G.; Eom, T.S. Cyclic loading test for reinforced-concrete-emulated beam-column connection of precast concrete moment frame. ACI Struct. J. 2013, 110, 115-126. [CrossRef]

33. Eom, T.S.; Park, H.G.; Hwang, H.J.; Kang, S.M. Plastic hinge relocation methods for emulative pc beam-column connections. J. Struct. Eng. 2015, 142, 04015111. [CrossRef]

(C) 2018 by the authors. Licensee MDPI, Basel, Switzerland. This article is an open access article distributed under the terms and conditions of the Creative Commons Attribution (CC BY) license (http:/ / creativecommons.org/licenses/by/4.0/). 